\title{
A família Lopes e a Inquisição no Brasil Colonial Quinhentista
}

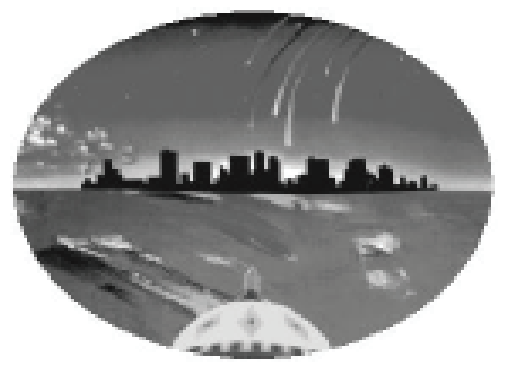

Emãnuel Luiz Souza e Silva*

\section{Resumo}

Este artigo tem como objetivo analisar a família de cristãos-novos, de Mestre Afonso e Maria Lopes, que viveu na Capitania da Bahia no final do século XVI. Este período foi marcado pelo envio da Primeira Visitação do Santo Ofício às partes do Brasil (1591-1595). O grupo familiar foi vítima de inúmeras denúncias de criptojudaísmo, que o colocou como alvo potencial da repressão inquisitorial, representada pelo então Visitador Heitor Furtado de Mendonça. A partir desta Visitação podemos observar o rol de culpas atribuídas e confessadas por este núcleo familiar, as relações sociais entre cristãos-novos e cristãos-velhos na sociedade baiana colonial e a ação da Inquisição Lisboeta em terras de além-mar.

Palavras-chave: Inquisição. Criptojudaísmo. Cristãos-novos. Brasil Colonial.

\begin{abstract}
This article aims to analyse the of Family Christian-new, from Mestre Afonso and Maria Lopes, who Lived in Bahia Captaincy in the end of the sixteenth century. This period was marked by the sending of the First Visitation of the Holy Office to parts of Brazil (1591-1595). The family group was the victim of numerous accusations of crypto-judaism, which posed as a potential target of inquisitorial repression, represented by then visitor Heitor Furtado de Mendonça. From this
\end{abstract}

\footnotetext{
* Mestrando em História - Universidade Estadual de Feira de Santana. Membro do Centro de Pesquisa da Religião (CPR). Email: emanoss@ig.com.br. Tel: (71)88336252. Agradeço à FAPESB - Fundação de Amparo à Pesquisa do Estado da Bahia, pela bolsa de estudos concedida.
} 
Visitation we can see the list of assigned blame and admitted by the family, social relations between Christians and Christian-new-old colonial in Bahia society and action of the Inquisition by Lisbon of land over seas.

Keywords: Inquisition. Crypto-judaism. New Christians. Colonial Brazil.

\section{Referenciais Passados: os Cristãos-novos em Portugal}

$\mathrm{Na}$ Península Ibérica, antes da instalação do Santo Ofício, habitavam grupos étnicos diversos. Além dos espanhóis e portugueses cristãos, também viviam aí, participando da sociedade destes países árabes, judeus e mouros. Os judeus em Portugal desempenhavam diversas funções na sociedade e interferiam significativamente na vida administrativa do país e na sua economia, onde alcançavam "posições de prestígio, tanto na área política como na econômicofinanceira." (NOVINSKY, 1996, p. 24). Eles foram médicos, filósofos, professores, astrônomos, tendo um padrão de vida comparável ao da aristocracia.

Como conseqüência da reconquista espanhola ocorreu a ordem, por parte dos soberanos católicos da Espanha, Fernando II de Aragão e Isabel I de Castela, para expulsarem os judeus que não quisessem se converter ao catolicismo. Este fato ocasionou, assim, a fuga em massa de milhares de famílias que cruzaram as fronteiras daquele território em busca da liberdade religiosa. Esta posição monárquica baseou-se na fundamentação de que somente poderia haver uma centralização real consistente com a unidade de fé. Neste ínterim aumentou-se o rigor sobre a religião. Grande parte destes judeus partiram da Espanha para Portugal, onde ainda existia uma relativa harmonia entre estes e os portugueses, se comparado ao país vizinho:

no que diz respeito às relações entre judeus e cristãos, podemos dizer que em Portugal [...] a religião não impediu nem prejudicou seriamente os contactos mútuos, as inter-relações grupais, sendo mesmo considerável o número de casamentos mistos. $\mathrm{O}$ povo não levava muito a sério as proibições dos representantes 
da igreja e os monarcas portugueses foram muitas vezes recriminados de Roma por favorecerem aos judeus. (NOVINSKY, 1992, p. 27.)

Cinco anos depois da ordem imposta pelos reis espanhóis para expulsão dos judeus não convertidos de sua terra, o rei português D. Manuel, o Venturoso, também impôs a conversão forçada em seu reino, proibindo as livres crenças e demarcando um prazo para a expulsão. Porém diferentemente do ocorrido na Espanha, os seguidores de Moisés foram proibidos de sair de Portugal. Assim, estes foram forçados à conversão e também à permanência em solo português.

Os que não conseguiram fugir de Portugal, e permaneceram neste território, foram convertidos à força e passaram a ser tratados como cristãosnovos. Esta expressão se tornou sinônimo de algo impuro, infecto, indigno, de pouca confiança. Eram vistos como os responsáveis pelas crises econômicas, as pestes, manifestações da natureza, entre outros aspectos sociais, cotidianos. Considerados cristãos fictícios, judeus batizados à força, sem apego à Igreja (SALVADOR, 1969, p. XX.), mesmo aqueles que, a partir de então, abraçaram aquela nova religião.

Em Portugal, no ano de 1536, a Inquisição recebeu autorização para funcionar. Por razões divergentes entre esse país e a Cúria Romana, o Tribunal só foi realmente estabelecido 11 anos depois (PIERONI, 2003, p. 34.) com a Bula do Papa Paulo III Meditatio Cordis. Naquele novo contexto, o cotidiano e a convivência entre cristãos-novos e velhos passou a ser caracterizada por uma intensa perseguição, tão implacável quanto na Espanha.

A partir da primeira metade do século XVI, um número crescente de cristãos-novos, além de buscarem novas possibilidades econômicas, passaram a desembarcar em solo brasileiro à procura de um local distante da metrópole onde tivessem maior liberdade religiosa. A América portuguesa foi então o local escolhido pela maioria destes cristãos-novos que saíram de Portugal, acreditando ser no Brasil mais difícil uma perseguição tão violenta quanto na metrópole. 
Atribuíam essa "possibilidade de paz" à distância e ao fato de ser a colônia "recém descoberta".

Assim começou a chegada de milhares de cristãos-novos ao Brasil, localizando-se em áreas estratégicas da colônia, tanto nas capitanias de Pernambuco quanto nas da Bahia, locais preferenciais para os que chegavam da metrópole. Além de serem as mais habitadas e desbravadas naquele período, aí se instalaram as capitanias mais prósperas e a sede do governo português no Brasil, atingindo o interesse da maioria da população.

Os cristãos-novos, uma vez na colônia, influenciaram na economia e tiveram uma relação com os cristãos-velhos de cordialidade e solidariedade, tendo-se em vista as dificuldades de convivência em solo colonial. Desempenharam funções importantes no desenvolvimento e crescimento da colônia portuguesa, até o momento em que a Inquisição enviou a sua Primeira Visitação do Santo Ofício às partes do Brasil dando fim a um relativo período de paz neste território.

\section{Os Cristãos-Novos na Sociedade Baiana}

Para entendermos as relações entre cristãos-novos e velhos na sociedade colonial do final do século XVI, devemos contextualizar esta relação dentro de características particulares que compõem a população, a religião, religiosidade, a economia e as práticas culturais destes sujeitos históricos que compartilharam as dificuldades do início da colonização e ocupação do solo. A partir daí, poderemos analisar a família cristã-nova de Maria Lopes e Mestre Afonso e a Primeira Visitação do Santo Ofício em terras brasileiras, que os perseguiu.

$\mathrm{Na}$ Capitania da Bahia, a cidade de Salvador foi fundada poucos anos após a instalação do Santo Ofício em Portugal, quando, em 1549, chegou em terras coloniais o primeiro Governador Geral do Brasil, Tomé de Souza. Junto com ele também veio o padre jesuíta Manuel da Nóbrega com a missão de trazer o cristianismo para as terras recém-colonizadas e converter a população nativa e/ ou recém-desembarcada. 
No período de administração dos três primeiros Governos Gerais, que abrangeu de 1549 a 1572, uma política efetiva de dominação do gentio e de demarcação de territórios foi implantada. A expansão populacional portuguesa passou a avançar da costa para os sertões, de forma gradativa e concomitante ao genocídio de milhares de índios que foram obrigados a ceder seu espaço territorial e cultural a um novo padrão de convivência imposto pela Igreja e pelo Estado. Este projeto começou no governo de Tomé de Souza e teve o seu ápice com o terceiro Governador Geral, Mem de Sá.

Assim, com este artifício expansionista, os portugueses continuaram a sua campanha de dominação e submissão dos ameríndios. Estes gentios que antes tinham seus costumes, suas adorações, seu cotidiano de tarefas e suas escolhas, se viram pressionados a obedecer a regras e em pouco tempo desfazer-se de todo o seu passado em prol de valores, costumes e de uma religião que não lhes era familiar, tudo isso em beneficio do desenvolvimento colonial.

Os cristãos-novos estavam presentes em todos os momentos desta ocupação, acompanhando os processos de expansão territorial e auxiliando no desenvolvimento da colônia. Tem-se a presença, desde a descoberta, de um cristão-novo na frota de Pedro Álvares Cabral "um homem chamado Gaspar da Gama." (WIZNITER, 1966, p. 2).

Neste contexto eles chegaram gradativamente, ocupando com os cristãosvelhos o território e superando as dificuldades existentes neste primeiro momento de colonização. Foram desbravadores do sertão, lavradores, mestres de açúcar, soldados, ajudando nas mais variadas atividades o desenvolvimento da Capitania. Sobre esta migração podemos observar: "Os cristãos novos chegam pouco a pouco, continuando um movimento migratório iniciado em princípios do século XVI, e que a partir da segunda metade se tornou mais intenso"(NOVINSKY, 1992, p. 57).

A população colonial, em sua maioria, estava concentrada neste primeiro século de colonização no litoral, devido à maior facilidade para a comunicação 
com a metrópole e ao pequeno avanço da penetração para os sertões. Quanto à composição social dessa população que habitava a colônia, parte dela era composta por degredados, pessoas indesejáveis na metrópole que eram enviadas à colônia para pagarem por algum crime, sendo ele moral, civil ou contra a fé (PIERONI, 2000, p. 11-12).

O caráter do degredo variava entre provisório ou permanente. Sendo provisórios, os degredados e a sociedade portuguesa viam o Brasil como um purgatório, onde este pecador e/ou infrator vinha pagar suas penas e posteriormente poderia voltar à metrópole. Variavam geralmente de 3 a 10 anos.

Houve inúmeros casos de cristãos-novos que foram degredados para $\mathrm{o}$ Brasil, por continuarem a praticar sua antiga fé, por crimes morais e/ou civis. Um caso de condenação por criptojudaísmo foi o de Fernão Dias, um negociante, natural e residente em Lamengo, Portugal, filho de Gabriel Dias e Micia Gomes, ambos cristãos-novos. Ele foi acusado na Inquisição de Lisboa por judaísmo, também contando contra ele a prisão de seu pai e sua tia pela Inquisição de Coimbra. Acabou sendo preso em 1578 e degredado para o Brasil por três anos. (PIERONI, 2003, p.139).

O açúcar neste momento histórico passou a ter grande importância econômica na colônia e seus produtores ocupavam o lugar dos "homens bons". A partir de 1570, quando, no recôncavo baiano, o cultivo da cana começou a se expandir, o açúcar foi ocupando os primeiros lugares na pauta das exportações brasileiras, influenciando na formação da sociedade e na administração do governo no Brasil, que se voltou a uma produção cada vez mais consistente deste produto (SCHAWRTZ, 1979, p. 79). Devido a este crescimento na produção do açúcar foi que se intensificou a utilização de mão-de-obra escrava, sendo efetuado pelos negros vindos, em sua maioria de Angola e da costa oeste da África.

Ser senhor de engenho na Bahia no final do século XVI representava ter prestígio e poder, pois ele detinha a produção do açúcar e a propriedade dos 
escravos, sinônimos de poderio e riqueza. Assim, o papel do senhor de engenho se destacava pela grandiosidade e influência, este que "era dono do seu engenho, da sua capela, dos seus escravos, da sua família." (CALMON, 1937, p. 79).

Dentro deste contexto, pode-se afirmar que muitos cristãos-novos que viviam na Bahia, naquele período, eram senhores de engenho. Podemos observar, então, um dos papéis sociais ocupados por este grupo na colônia. Sobre a importância desta condição: "A condição de senhor de engenho já conferia ao cristão-novo como ao velho uma posição de relevo, semelhante à do fidalgo" (NOVINSKY, 1992, p. 59).

Um caso conhecido destes sujeitos sociais, constatado nas Confissões e Denunciações da Primeira Visitação do Santo Ofício à Bahia foi o da família Antunes, dona de um engenho no recôncavo baiano, em Matoim. O patriarca da família já havia morrido, porém foi alvo de muitas denúncias. Ele construiu seu engenho e era homem de posses, bem relacionado com a elite e o poder local, prova disto é que todas as suas filhas, mesmo sendo cristãs-novas se casaram com cristãos-velhos de posses.

Uma prova da integração dos cristãos-novos na sociedade baiana foram os casamentos mistos. Na Primeira Visitação do Santo Ofício se percebe um número considerável de pessoas que se denominavam $1 / 2$ cristãs-novas devido a estas relações. Um caso para exemplificar é o de Clara Fernandes, que era filha de Antonio Peneiro, cristão-novo, e de Gracia Dias, cristã-velha. Clara Fernandes foi casada com Manuel Fernandes, cristão-velho (VAINFAS, 1997, p. 83).

Sobre essas posições ocupadas por cristãos-novos na sociedade baiana Stuart Schwartz complementa que "Na Bahia, os cristãos-novos se integraram bem na população e na vida econômica da capitania; participavam não só dos aspectos comerciais, mas também dos agrícolas e da produção de açúcar." (SCHWARTZ, 1979, p. 87). Eles também tiveram postos na governança e na administração: foram vereadores, juízes ordinários, meirinhos, solicitadores, 
além das profissões liberais como médicos, advogados, entre outros cargos. (NOVINSKY, 1992, p. 60).

Sobre a religião na colônia, esta se caracterizou pela superficialidade, apesar de ser predominante e interferir significativamente na vida da sociedade baiana. O catolicismo se fazia valer no espaço colonial para legitimar a conquista. Muitos aspectos cotidianos de convivência eram determinados pelo poder eclesiástico: as relações matrimoniais, as relações familiares, o papel da mulher e do homem na sociedade, as normas da vida sexual, as relações de sociabilidade através das festividades e das missas dominicais, enfim uma gama de possibilidades fazia com que a Igreja interferisse diretamente na vida da população baiana.

Através destas Denunciações e Confissões da Bahia, se descortina o cotidiano dos cristãos-novos, com a permanência de certos costumes judaicos, que foram denunciados por vizinhos, parentes e amigos destes sujeitos sociais. Também as suas confissões revelam aspectos de uma tradição que mesmo proibida e discriminada persistia em muitos lares dos considerados "impuros de sangue".

As práticas costumeiras que continuaram na colônia e podem ser observadas com mais freqüência através da documentação inquisitorial foram: a utilização de roupas limpas aos sábados, mandar vazar fora a água de casa quando alguém morria, fazer juramento judaico: "pelo mundo que tem a alma de meu pai" (VAINFAS, 1997, p. 132); guardar os sábados e mandar trabalhar nos dias santos. Outros costumes acompanhavam estes sujeitos e faziam com que eles não perdessem totalmente as ligações com a sua antiga religião, mesmo realizando estas tradições às escondidas e tendo que adaptá-las ao interior de suas casas, em lugares reservados, onde pudessem realizá-los sem constrangimentos.

Muitos também utilizavam o interior de suas moradas para se vingarem da religião que os oprimia, através de blasfêmias, do açoite às imagens de santos católicos, colocando-as em lugares inapropriados como: debaixo da cama ou no 
local onde faziam suas necessidades corpóreas. Essas eram as mais comuns entre outras manifestações de revolta.

O cristão-novo Álvaro Sanches foi se confessar por ter maltratado o desenho de Nossa Senhora (VAINFAS, 1997, p. 100). A cristã-nova Clara Fernandes foi denunciada por ter mandado fazer um crucifixo de prata e depois de recebê-lo, colocou em uma almofada, sobre a qual ela se sentava (MENDONÇA, 1925, p. 269). Ela também foi denunciada por açoitar um crucifixo (MENDONÇA, 1925, p. 285). Porém, havia também cristãos-novos que viviam de acordo com a sua nova realidade religiosa: iam às missas, tinham oratório em casa, rezavam de acordo com a fé católica, se benziam, seguiam à risca os ensinamentos dos padres e conversavam sobre a sua nova religião. Alguns deles confessaram para o Visitador outros delitos contra a fé, que não estavam submetidos ao judaísmo.

Esta denominação cristão-novo era vista com depreciação na colônia, onde também impunha sua condição de "inferioridade". A primeira pessoa a denunciar, no dia 29 de julho de 1591, na mesa, perante o Visitador, foi João Serrão. Neste primeiro momento se denominou cristão-velho inteiro, porém no dia 22 de agosto ele compareceu novamente ao Santo Ofício, para se confessar e disse que havia mentido sobre ser cristão-velho, na verdade era cristão-novo inteiro, revelando, assim, uma convivência não tão harmoniosa quanto se pensa entre cristãos-novos e velhos na Bahia. Sobre ser cristão-velho ele afirmou:

e dise aver nome como ditto he e ser cristão velho de todas as partes natural de Bragança filho de Francisco de Chaves e de Clara Seram casado com Constança de Pina, lavrador de idade de quarenta annos pouco mais ou menos, morador em Tasuepina freguesia de Nosa Senhora do Socoro. (MENDONÇA, 1925, p. 237).

Já em sua confissão no dia 22 de agosto, disse que:

elle he cristão novo inteiro filho de Francisco de Chaves cristão novo alfaiate e de sua molher Clara Seram cristan nova [...] e isto fizera por elle estar casado nesta cidade com huma molher 
cristã velha de gente limpa e abastada e elle ser tido por todos cristão velho... avido em boa conta e honrado. (MENDONÇA, 1935, p. 43.).

Assim podemos observar um pouco da vida cotidiana e costumes da população baiana no final do século XVI: suas sociabilidades e as características da cidade de Salvador e da Capitania da Bahia. Observamos também o comportamento dos cristãos-novos, que se adaptavam a esta nova realidade colonial integrando-se a esta sociedade que então se formava pouco antes da chegada do visitador Heitor Furtado de Mendonça e de sua comitiva em uma Visitação Inquisitorial à Bahia. Sobre a integração dos cristãos-novos na sociedade baiana:

miscigenou-se com a população nativa, criou raízes profundas na nova terra, integrando-se plenamente na organização social e política local. Esta organização, ao mesmo tempo permitiu a integração e acomodação do cristão-novo, sofreu reciprocamente, deste, profunda influência. (NOVINSKY, 1992, p. 58).

A Visitação durou dois anos e desestruturou, pelo menos temporariamente, laços de amizade e familiares, além da incessante busca pelos criptojudaizantes que estavam pondo em risco a supremacia religiosa da Igreja Católica.

\section{A Visitação do Santo Ofício à Bahia}

Quando a Inquisição veio ao Brasil, no final do século XVI, muitos cristãosnovos já haviam sido denunciados e presos pelo Santo Ofício na metrópole. Vários Autos de Fé aconteceram e muitas pessoas foram condenadas à fogueira. Em Portugal, este número cresceu consideravelmente tendo, entre os principais acusados e punidos, os que ainda praticavam o judaísmo, mesmo às escondidas.

Esta perseguição e as punições do Tribunal causaram a fuga de muitos cristãos-novos para o Brasil. Um exemplo, dentre muitos, é o de Pedro Homem, descendente de judeus que veio à colônia e foi morador na casa do seu parente 
Tristão Ribeiro. Passou alguns anos na Bahia, depois voltou para Portugal. Em 1591 veio novamente a estas terras, porém houve denúncias que diziam que este saiu de Portugal fugido da Santa Inquisição, pois sua irmã havia sido presa pelo Tribunal. (MENDONÇA, 1925, p. 415).

Durante meio século aproximadamente, estes sujeitos sociais viveram em relativa harmonia com os cristãos-velhos superando as adversidades e adaptando as suas vidas ao cotidiano e às novas condições que a vida na colônia proporcionava. Este ambiente começou a se desestruturar quando o arquiduque Alberto da Áustria, que em 1586 era vice-rei de Portugal, foi constituído inquisidor geral dos reinos e senhorios portugueses (MENDONÇA, 1935, p. V). Já com esta titulação "Ordenou a primeira visitação do Santo Officio às partes do Brasil." (MENDONÇA, 1935,p. 5). No dia 26 de março de 1591, Heitor Furtado de Mendonça foi nomeado visitador e lhe foi determinado que a sua visitação abrangesse os bispados de Cabo Verde, São Tomé, Brasil e a administração de S. Vicente ou Rio de Janeiro.(MENDONÇA, 1935, p. 5).

A Primeira Visitação objetivava a busca de sujeitos sociais que de alguma maneira pudessem atrapalhar o controle moral e religioso imposto pela Igreja Católica. Além dos cristãos-novos, havia também as pessoas que cometiam crimes sexuais, como a sodomia, o bestialismo, enfim, as relações que não seguissem o padrão estipulado pelo catolicismo. As práticas mágicas e a feitiçaria, os blasfemos, os que praticavam o luteranismo, todos estes "delitos" eram punidos pelo Santo Ofício.

Heitor Furtado de Mendonça, nesta Visitação, recebeu muitas confissões e denúncias de cristãos-novos judaizantes e de uma certa abusão indígena chamada Santidade. Os mais denunciados foram os integrantes da família de Heitor Antunes, em Matoim, acusados de manterem uma sinagoga de judeus, e Fernão Cabral de Taíde, responsável por abrigar a idolatria indígena.

Dentro desta possibilidade que a documentação inquisitorial disponível traz, buscamos analisar mais profundamente um grupo de cristãos-novos que 
também foi denunciado nesta Primeira Visitação: a família de Mestre Afonso e de Maria Lopes. A partir daí compreendemos como foi a visitação, como se realizavam as denúncias e confissões, como esta família reagiu à presença do Santo Ofício; se eles eram judeus convertidos ou realmente criptojudaizantes, seu cotidiano familiar, as sua práticas e como este grupo estava inserido na sociedade baiana colonial.

A família de Afonso Mendes e Maria Lopes nunca foi alvo de um estudo aprofundado e específico, porém, citados em alguns trabalhos em abordagem geral. Este grupo familiar é bastante extenso e permitirá, através das suas minuciosas confissões e das denúncias a eles feitas, adentrarmos no seu cotidiano e reconstituirmos, mesmo que não seja de forma plena e absoluta, a história dessas pessoas que viveram, se instalaram e influenciaram a sociedade colonial baiana.

A chegada dos primeiros integrantes desta família ocorreu a partir da segunda metade do século XVI. Afonso Mendes havia sido nomeado cirurgiãomor do Brasil e aportou em terras brasileiras em 28 de dezembro de 1557. Sobre a sua família pouco se conhece pela documentação das Visitações, somente que ele era cristão-novo. Viajou na mesma nau que trouxe o governador Mem de Sá e Heitor Antunes, patriarca da família Antunes. Posteriormente, a família foi ocupando diversas localidades da Bahia. Nas beiras do Paraguaçu, capitania de Porto Seguro, capitania de Ilhéus, em Paripe, mas a maioria era residente em Salvador.

A convivência desta família com a sociedade baiana era relativamente harmoniosa, até a chegada do Santo Ofício na Bahia. Maria Lopes era lavadeira e mantinha relações com um grande número de pessoas. Este convívio pode ser confirmado pela presença de cristãos-velhos que freqüentavam a casa de mestre Afonso, como por exemplo, Beatriz da Silva, que passou alguns dias em sua casa. (MENDONÇA, 1925, p. 540); as filhas de Diogo Sorilha: Maria 
Sorilha e Antônia Fogaça, que eram amigas de Branca de Leão e se visitavam (MENDONÇA, 1925, p. 242).

Eles também mantinham relações com cristãos-novos fora de seu núcleo familiar como a matriarca da família Antunes, Ana Roiz, com quem Maria Lopes manteve amizade durante um certo tempo. Muitos dos que os denunciaram eram amigos ou freqüentavam as suas casas, com quem mantinham estreitas relações.

Interessante registrar que esta família não entrava em conflito com a religião católica de forma aberta, pois seus integrantes freqüentavam as igrejas, assistiam às missas, tinham imagens de santos, oratórios, cruzes em suas casas e realizavam grande parte das obrigações religiosas que uma família católica colonial deveria realizar. Eles, porém, não ficaram completamente submissos às imposições do catolicismo e sempre encontraram uma maneira de extravasar as suas vontades interiores e a suas revoltas, deixando viva, mesmo de forma escamoteada, a sua verdadeira religião.

Sobre a presença de membros desta família no cotidiano religioso da colônia, temos alguns exemplos: No mesmo ano em que a Visitação chegou na Bahia, três ou quatro meses antes, Álvaro Pacheco estava ouvindo uma missa no dia de Nossa Senhora da Ajuda, na Igreja da Sé. O capelão cantou uma epístola e passou do interior da igreja em direção à saída, neste momento ele comentou com o cristão velho Gaspar Dias, sentado ao seu lado "como aquelle vai contente parecendo-lhe que disse alguma cousa”. (MENDONÇA, 1925, p. 245).

Aquela frase causou grande espanto, por ser cristão-novo e dizer que a epístola da missa não era nada. Por isso foi denunciado a Heitor Furtado (MENDONÇA, 1925, p. 245). Sua irmã, Ana de Oliveira também foi denunciada ao Santo Ofício por se comportar mal quando ia à igreja. Sempre procurava alguém para conversar na hora da missa e não rezava, brincando com as contas na mão. Também foi denunciada por ficar:

inquieta e com pouca reverencia a deos falando com todas folgando com as contas sem rezar nada por ellas e lhe lembra que 
duas vezes se não alevantou ao Evangelho, e se ficou assentada a elle sendo sã e bem disposta e que isto escandalizou a ella denunciante por ella ser cristã nova. (MENDONÇA, 1925, p. 377)

Podemos observar algumas práticas desta família que foram registradas pela Visitação do Santo Ofício à Bahia. Maria Lopes, por exemplo, foi se confessar no dia 3 de agosto de 1591, e já havia sido denunciada. ${ }^{1}$ No primeiro dia apresentou as seguintes culpas: em casa, quando mandava matar uma galinha, a degolava e, às vezes em que assava um carneiro ou porco para comer, tirava a gordura; cozinhava as carnes também com azeite. Todas estas formas de preparo eram cerimônias judaicas.

Durante a confissão o Visitador tentou, através de seus métodos intimidadores, fazer com que ela confessasse mais, afirmando que aquelas práticas eram conhecidas como judaicas e, como era cristã-nova, melhor seria dizer a verdade, pois “está em tempo de graça no qual merecera larga misericórdia da Santa Igreja" (VAINFAS, 1997, p. 33). Porém, Maria Lopes persistiu e afirmou que não tinha intenção de ofender a Deus e que era boa cristã.

Dias depois, foi se confessar novamente, o que pode demonstrar duas posturas: ou o medo de uma punição por parte do Visitador pelas suas práticas e por ter como antecedente acusatório a sua descendência judaica, ou a tentativa de mostrar que verdadeiramente tinha abraçado o catolicismo em detrimento da religião judaica, e com as suas confissões colaborar efetivamente com o representante da Igreja Católica naquele momento.

Outros membros desta família também foram se confessar perante Heitor Furtado de Mendonça: Diogo Afonso, filho de Maria Lopes, foi o único que se confessou por pecados que não envolviam práticas judaicas. Compareceu à mesa para contar sobre suas aventuras amorosas com Fernão Campo, tendo cometido ajuntamento carnal e efetuado o pecado da sodomia. (VAINFAS, 1997, 268). Também se confessaram Antônia de Oliveira e Catarina Mendes, irmã de Maria Lopes. 
Com relação às denúncias, podemos observar que a família em evidência foi alvo de inúmeras, perfazendo um total de aproximadamente $20 \%$ das 212 denunciações registradas pelo Visitador. Tivemos, entre os membros deste grupo familiar denunciados por esta Visitação: Branca de Leão, Maria Lopes, Álvaro Pacheco, Mestre Afonso, Salvador da Maia, Catarina Mendes, Leonor da Rosa, Gaspar Dias da Vidigueira, Antonio Serrão, Antonio Lopes Ulhoa, Diogo Lopes Ulhoa, Antônia de Oliveira, Diogo Afonso, Fernão Lopes, Branca Rodrigues, Violante Rodrigues, dentre os quais alguns já haviam morrido na época da Visita, mas nem por isso deixaram de ser lembrados no momento da denúncia. Interessante notar que o único membro da família que denunciou foi Pero Fernandes, marido de Antonia de Oliveira, e o fez contra um parente, Álvaro Pacheco.

Através desta denúncia, percebemos que os laços familiares começaram a se quebrar, salientando, mais uma vez, a força que o catolicismo tinha no final do século XVI: um membro da família denunciando o outro, como se assim se excluísse do grupo familiar e também mantivesse afastada a sua mulher de qualquer tipo de culpa, em detrimento dos demais. As denúncias variavam entre, práticas judaizantes e as "descortesias" feitas a imagens de santos católicos, realizadas através de açoites e blasfêmias. Ocorreram também algumas práticas que escandalizaram a população, por isso eram conhecidas, como quando se encontrou um retábulo enterrado na antiga propriedade da família, não se sabe de que imagem.

Sobre Maria Lopes pesaram as culpas de não trabalhar aos sábados (MENDONÇA, 1925, p. 323), ter uma imagem dentro de uma almofada, na qual mandava que as moças se sentassem quando iam a sua casa (MENDONÇA, 1925, p. 410). Ela também foi acusada de açoitar um crucifixo (MENDONÇA, 1925, p. 547).

Mestre Afonso também foi bastante denunciado. As culpas principais foram: ter um crucifixo e açoitá-lo nas sextas-feiras (MENDONÇA, 1925, 
p. 489), comer carne em dia que a igreja defende, não trabalhar aos sábados (MENDONÇA, 1925, p. 487), fazer descortesias a um crucifixo do menino Jesus quando estava dentro de casa. (MENDONÇA, 1925, p. 487).

\section{Considerações finais.}

Ao término da Visitação à Capitania da Bahia, o visitador havia se deparado com algumas culpas já conhecidas pela sua experiência na metrópole, mas também com particularidades de uma colônia recém-descoberta, composta por uma população heterogênea. Muitas pessoas foram até à mesa do Santo Ofício para acusarem desvios das mais variadas qualificações, muitos dos quais não competiam ao jugo do Tribunal. Assim o Visitador foi obrigado a julgar também o que desconhecia como as culpas da Santidade de Jaguaripe.

Sobre as persistências e continuidades que o Santo Ofício havia trazido à população baiana:

na Bahia tudo voltaria a ser como antes, exceto pelos ressentimentos que a passagem do visitador havia deixado na sociedade local. Maridos haviam denunciado esposas, e vice-versa; filhos haviam delatado seus pais e avós [...] O Santo Ofício deixara, em seu rastro, a marca de sua ação deletéria e a memória de seus autos-de-fé [...] Ressentimentos e medos à parte, a vida colonial baiana retomou o seu cotidiano monótono (VAINFAS, 1995, p. 211.).

Através desta documentação inquisitorial disponível nas confissões e denunciações da Bahia, tivemos a oportunidade de resgatar a história e a trajetória de uma família do final do século XVI e revelarmos os seus costumes, o seu cotidiano e as suas relações sociais em conexão com a sociedade baiana daquele período. Isto se deve às possibilidades que estes documentos nos propiciam. Assim conseguimos trazer à tona um grupo familiar que, sem os registros deixados por essa Visitação, não poderia ter sido objeto de um estudo histórico. 
Percebemos na documentação que quase todos os membros da família foram denunciados, contrastando com o número de confissões - foram apenas quatro: Maria Lopes, Antônia de Oliveira, Catarina Mendes e Diogo Afonso. Somente um deste grupo denunciou e, mesmo assim, foi ao Visitador para acusar seu parente: Álvaro Pacheco, que foi denunciado por Pero Fernandes. Também se evidenciou quem eram as pessoas que as denunciavam, seu grau de aproximação com estes membros e por que foram alvos de tantas denúncias. Para este estudo não foram utilizadas as denúncias e confissões contra esta família que constam na Visitação do Santo Ofício em Pernambuco (1593-1595). Somente foram levados em consideração à analise os casos ocorridos na Capitania da Bahia.

A chegada da Inquisição ao Brasil, que escolheu a Bahia para inaugurar suas atividades na colônia, procurou, além de outros motivos, conter os cristãosnovos que ainda estivessem praticando a sua antiga religião, revelando assim o poder da Igreja Católica. Através dos trabalhos realizados pelo Santo Ofício em solo baiano, buscamos analisar uma importante família de cristãos novos e como esta reagiu à presença desta Visitação.

Algumas respostas podem ser encontradas no término deste trabalho. Esta família, por ser composta, em sua maioria absoluta, de cristãos-novos, enfrentou o preconceito que esta condição lhe trazia, naquele contexto histórico. Sobre esta família e as punições ou processos instaurados contra membros deste grupo, sabemos que foram processados: Antonia de Oliveira, filha de Ana Rodrigues, Salvador da Maia, marido de Catarina Gomes, Mestre Roque, tio de Maria Lopes, Duarte Serrão, filho de Antonio Serrão e Catarina Mendes, e André Lopes Ulhoa, já na segunda Visitação. A partir destes processos também podemos ter uma noção das tramas e infortúnios desta família, que conheceu a força repressora da ação inquisitorial nas terras brasílicas no final do século XVI.

Através da esteriotipação que estes sujeitos sofriam, considerados impuros de sangue e pecadores, as denúncias revelam uma população extremamente 
excludente. A sociedade baiana e as autoridades lusas, que tinham como respaldo o Edital da Fé e o Monitório da Inquisição, iniciaram uma repulsa a estes descendentes de judeus, denunciando-os, desestruturando suas famílias, rompendo antigos laços de amizade que mantinham, em prol de um padrão de comportamento estipulado pela Igreja Católica e a Metrópole portuguesa.

\section{Nota}

${ }^{1}$ No primeiro dia, 29 de julho, das atividades inquisitoriais na cidade.

\section{Referências}

CALMON, P. História social do Brasil: espírito da sociedade colonial. São Paulo, Companhia Editora Nacional, 1937. Tomo I.

MENDONÇA, H. F. de. Primeira visitação do Santo Ofício às partes do Brasil: Confissões da Bahia - 1591-1592. Rio de Janeiro: F. Briguiet, 1935.

- Primeira visitação do Santo Ofício às partes do Brasil: Denunciações da Bahia - 1591- 1593. São Paulo, Paulo Prado, 1925.

NOVINSKY, A. Inquisição. São Paulo: Brasiliense, 1996.

Cristãos-Novos na Bahia: A Inquisição. São Paulo: Perspectiva, 1992.

PIERONI, G. Banidos: a Inquisição e a lista dos cristãos-novos condenados a viver no Brasil. Rio de Janeiro: Bertrand Brasil, 2003.

PIERONI, Geraldo. (2000). Vadios e Ciganos, Heréticos e Bruxas. Rio de Janeiro, Bertrand Brasil.

SALVADOR, J. G. Cristãos-novos, Jesuitas e Inquisição: aspectos de sua atuação nas capitanias do Sul. (1530-1680). São Paulo: Livraria Pioneira Editora, 1969.

SCHWARTZ, S. B. Burocracia e Sociedade no Brasil Colonial. São Paulo: Editora Perspectiva, 1979.

VAINFAS, R. A Heresia dos Índios: Catolicismo e Rebeldia no Colonial. São Paulo: Companhia das Letras, 1997. 
- (org). Santo Ofício da Inquisição de Lisboa: confissões da Bahia. São Paulo:

Companhia das Letras, 1997.

WIZNITZER, A. Os Judeus no Brasil colonial. São Paulo, Livraria Pioneira Editora, 1966. 